\title{
Re-use of Collateral: Leverage, Volatility, and Welfare*
}

\author{
Johannes Brumm \\ Karlsruhe Institute of Technology \\ johannes.brumm@kit.edu \\ Felix Kubler \\ University of Zurich \\ and Swiss Finance Insitute \\ kubler@bf.uzh.ch
}

\author{
Michael Grill \\ European Central Bank \\ michael.grill@ecb.europa.eu \\ Karl Schmedders \\ University of Zurich \\ and Swiss Finance Insitute \\ karl.schmedders@business.uzh.ch
}

February 6, 2017

\begin{abstract}
We assess the quantitative implications of the re-use of collateral on financial market leverage, volatility, and welfare within an infinite-horizon asset-pricing model with heterogeneous agents. In our model, the ability of agents to re-use frees up collateral that can be used to back more transactions. Re-use thus contributes to the build-up of leverage and significantly increases volatility in financial markets. When introducing limits on re-use, we find that volatility is strictly decreasing as these limits become tighter, yet the impact on welfare is non-monotone. In the model, allowing for some re-use can improve welfare as it enables agents to share risk more effectively. Allowing reuse beyond intermediate levels, however, can lead to excessive leverage and lower welfare. So the analysis in this paper provides a rationale for limiting, yet not banning, re-use in financial markets.
\end{abstract}

Keywords: Heterogeneous agents, leverage, re-use of collateral, volatility, welfare.

JEL Classification Codes: D53, G01, G12, G18.

${ }^{*}$ We thank audiences at the European Central Bank and the 2016 EEA Meeting in Geneva for helpful comments. Felix Kubler and Karl Schmedders gratefully acknowledge the financial support of Swiss Finance Institute. Johannes Brumm and Felix Kubler acknowledge the support of the ERC. The opinions expressed in this paper are those of the authors and should not be regarded as those of the European Central Bank or the Eurosystem. 


\section{Introduction}

Re-use and re-hypothecation of collateral has become a major activity in financial markets. It refers to the practice of financial institutions to use collateral received in one transaction for another transaction 11 Global collateral re-use at the onset of the financial crisis was estimated to be up to US $\$ 6.6$ trillion, and dropping to US $\$ 3.4$ trillion at the end of 2010, see Singh (2011) 2 While market participants have stressed the importance of re-use of collateral as a source of funding and market liquidity more generally, regulators and supervisors have raised various concerns about this market practice. For example, the Vice-President of the ECB, Vítor Constâncio, has stressed that "activities of re-hypothecation and re-use of securities amplified the creation of chains of inside liquidity and higher leverage" 3 Moreover, the Financial Stability Board (FSB) has recently publishes work that analyzes the financial stability implications of collateral re-use (see FSB (2017a)). Furthermore, several regulatory frameworks already foresee specific rules like limits and transparency requirements for re-use of (non-cash) collateral. For example, European retail investment funds (UCITs) are banned from re-using non-cash collateral. Moreover, the EU framework for margin requirements for non-centrally cleared derivatives foresees a ban of re-use of non-cash collateral that is posted as initial margin. Given the importance of collateral re-use in financial markets and the need to inform the ongoing regulatory initiatives, it is important to develop a model framework to understand the (quantitative) implications of collateral re-use on financial market outcomes and welfare.

Building on Brumm et al. (2015), we develop an infinite-horizon asset-pricing model with heterogeneous agents that allows us to assess the quantitative implications of re-use on financial market leverage, volatility, and welfare. In our model, the ability of agents to re-use frees up collateral that can be used to back more transactions. Through this channel, re-use of collateral contributes to the build-up of leverage and is found to significantly increase volatility in financial markets. When we introduce limits on the amount of collateral that agents may re-use, we find that volatility is strictly decreasing in the tightness of the re-use limit. While the effect of re-use limits on volatility is monotone, the impact on welfare is not. In the model, allowing for some re-use can improve welfare as it enables agents to share risks more effectively. Allowing re-use beyond intermediate levels, however, can lead to excessive leverage and lower welfare. Thus, the analysis in this paper provides a rationale for limiting, yet not banning, re-use in financial markets.

In the economic model, financial securities are only traded if the promised payments associated with selling these securities are backed by collateral. The amount of collateral needed to back a

\footnotetext{
${ }^{1}$ Institutions typically receive collateral in securities financing transactions (SFTs, e.g., reverse repo, securities lending/borrowing) or derivative transactions, and if eligible for re-use, may post it as collateral in other transactions (e.g., for repos, securities lending/borrowing, derivatives collateral) or use if for short sales. Re-hypothecation typically refers to the use of client assets to obtain funding as to finance client activities and is considered as a subset of re-use activity.

${ }^{2}$ In a related and more recent study, Kirk et al. (2014) document that three large US dealer banks have a strong dependency on re-use of collateral for financing their activities, estimating their total amount of collateral re-use to be approx. US $\$ 1.3$ trillion at end-2013.

${ }^{3}$ V. Constâncio, Beyond traditional banking: a new credit system coming out of the shadows, Speech, University of Frankfurt, 17 October 2014.
} 
transaction is determined in equilibrium. Re-use of collateral is introduced by allowing agents who receive securities as collateral to sell these securities to other agents. As a consequence, the security can again be used to collateralize transactions allowing agents to further build up their leveraged position in the risky security. To generate collateralized borrowing in equilibrium we assume that there are two types of agents who differ in risk aversion and in their beliefs about the growth potential of the economy and the risky assets $4^{4}$ These agents have Epstein-Zin utility with identical intertemporal elasticity of substitution (IES) parameters and identical time discount factors. The agent with the low risk aversion parameter (agent 1) and optimistic beliefs is the natural buyer of risky assets and takes up leverage to finance these investments. The agent with the high risk aversion (agent 2) and pessimistic beliefs has a strong desire to insure against bad shocks and is thus willing to buy bonds thereby providing financing to the other agent. Growth rates in the economy reflect the possibility of disaster shocks as in Barro and Jin (2011). When the economy is hit by a bad shock, the leveraged agent 1 loses financial wealth. As a result, the collateral constraint forces him to reduce consumption and to sell risky assets to the risk-averse agent. These actions trigger an additional decrease in asset prices, which further reduces the wealth of agent 1 - thereby reinforcing the impact of the bad shock.

Introducing re-use of collateral into the model significantly increases volatility. More collateral becomes available in financial markets, allowing agents to build up leverage beyond what is feasible in a situation where no re-use of collateral is possible. As a consequence, introducing re-use limits constrains this build-up of leverage, and as the impact of negative shocks becomes less severe, volatility drops. In our welfare analysis, where we consider unanticipated changes in regulation, we find that intermediate levels of re-use limits are welfare optimal: Compared to very loose or very strict regulation, the welfare of one agents is increased when transfers are chosen such that the other agent's welfare is kept constant; in some cases we even observe Pareto improvements. The relation between re-use limits and welfare is non-monotone because two counteracting forces are at play: First, the ability to re-use allows for more risk-sharing in the economy. This is generally beneficial for welfare given the agent's heterogeneity in risk aversion. Second, the heterogeneity in agents' beliefs triggers agents to build up leveraged positions beyond what is needed to optimally share risks. As the ability to re-use collateral allows agents to build up this leverage, limiting re-use has the potential to steer agents' choices towards socially optimal levels.

There is a growing policy and academic literature on the role of re-use and re-hypothecation in financial markets. Singh and Aitken (2010), Singh (2011) and Kirk et al. (2014) use publicly available data to estimate the amount of collateral re-use in financial markets. Bottazzi et al. (2012), Andolfatto et al. (2015), Maurin (2015), and Gottardi et al. (2015) present theoretical models of collateral re-use. In particular, Bottazzi et al. (2012) provides a general theory of re-use in repo markets whereas Andolfatto et al. (2015) show how re-use may benefit the provision of liquidity in financial markets. Maurin (2015) focuses on the role of re-use in completing markets, whereas Gottardi et al. (2015) discuss how re-use may impact collateral constraints and haircuts. Furthermore,

\footnotetext{
${ }^{4}$ We assume that agents (agree to) disagree about the probability distribution of the growth rates. The agents' beliefs deviate from the objective probabilities in opposite directions, agent 1 being optimistic and agent 2 being pessimistic.
} 
Infante (2014) and Eren (2014) present models that consider the funding role of re-use for dealer banks. Eren (2014) shows how re-use may expose hedge fund to a dealer's default, whereas Infante (2014) considers how collateral runs may arise due to re-use. However, none of these papers provide a quantitative analysis of the implications of re-use on aggregate financial market outcomes. Furthermore, with the exception of Andolfatto et al. (2015), who discuss limits on re-use in the context of monetary policy and inflation and find that limits need to be stricter in economies with lower inflation or a lower rate of return on securities, none of these papers focusses on the implications of regulating re-use.

The remainder of this paper is organized as follows. Section 2 provides an overview of industry practices for collateral re-use. In Section 3 we describe our economic model and its benchmark parametrization. Section 4 presents numerical results for the impact of re-use on leverage and volatility in the benchmark economy. In Section 5 we examine the welfare implications of re-use limits. Section 6 concludes. The Appendix contains additional proofs.

\section{An overview of collateral re-use practices}

Since the academic literature on the re-use of collateral is still very young, we begin with a brief description of re-use in industry practice. For this purpose, we first define the terms re-use and rehypothecation. Next we provide some figures on the size of global re-use activities. Then we discuss some regulatory concerns about the effects of collateral re-use on the stability of financial markets. We complete our introduction with a look at recent initiatives at international level assessing financial stability risks and benefits associated with collateral re-use.

\subsection{Defining re-use of collateral}

The Financial Stability Board (FSB) defines collateral re-use in a broad sense as "any use of assets delivered as collateral in a transaction by an intermediary or other collateral taker", see FSB (2017b). Financial institutions receive collateral in securities financing transactions (SFTs, e.g., reverse repo, securities lending/borrowing) or derivative transactions. Depending on the terms of the transaction, the collateral may be eligible for re-use by the receiving counterparty: they can use it for their own purposes (e.g., for repos, securities lending/borrowing, short sales, derivatives collateral). For example, in a repurchase transaction (repo), the counterparty providing cash (i.e. the collateral taker) can re-use the securities obtained as collateral to, among other things, pledge as collateral in a separate transaction with a third party. Often, the term "collateral re-use" is used interchangeably with the term "re-hypothecation". Again, we follow FSB (2017b) where re-hypothecation is defined narrowly as "any use by a financial intermediary of client assets". We therefore consider re-hypothecation as a subset of the broad collateral re-use concept. In a typical re-hypothecation transaction, securities

that serve as collateral for a secured borrowing (e.g., a margin loan extended to a hedge fund) are further used by the intermediary to obtain funding for the initial transaction. 


\subsection{The relevance of collateral re-use in financial markets}

Re-use of collateral has become a major activity in financial markets, and is a common practice across many entities in the financial system. Though incomplete data makes it difficult at this junction to pin down the exact size of global collateral re-use activity, publicly available data on collateral re-use activity of globally active banks indicates that collateral re-use plays an important role in financial markets $5^{5}$ Figure $\mathrm{V}$ displays the evolution of re-use activity for a set of 13 global banks. The level of collateral re-use amongst the 13 global banks amounted to around 3.8 trillion euro and approximately $30 \%$ of total assets of these financial institutions before the crisis. The time

Figure I: Collateral Re-use

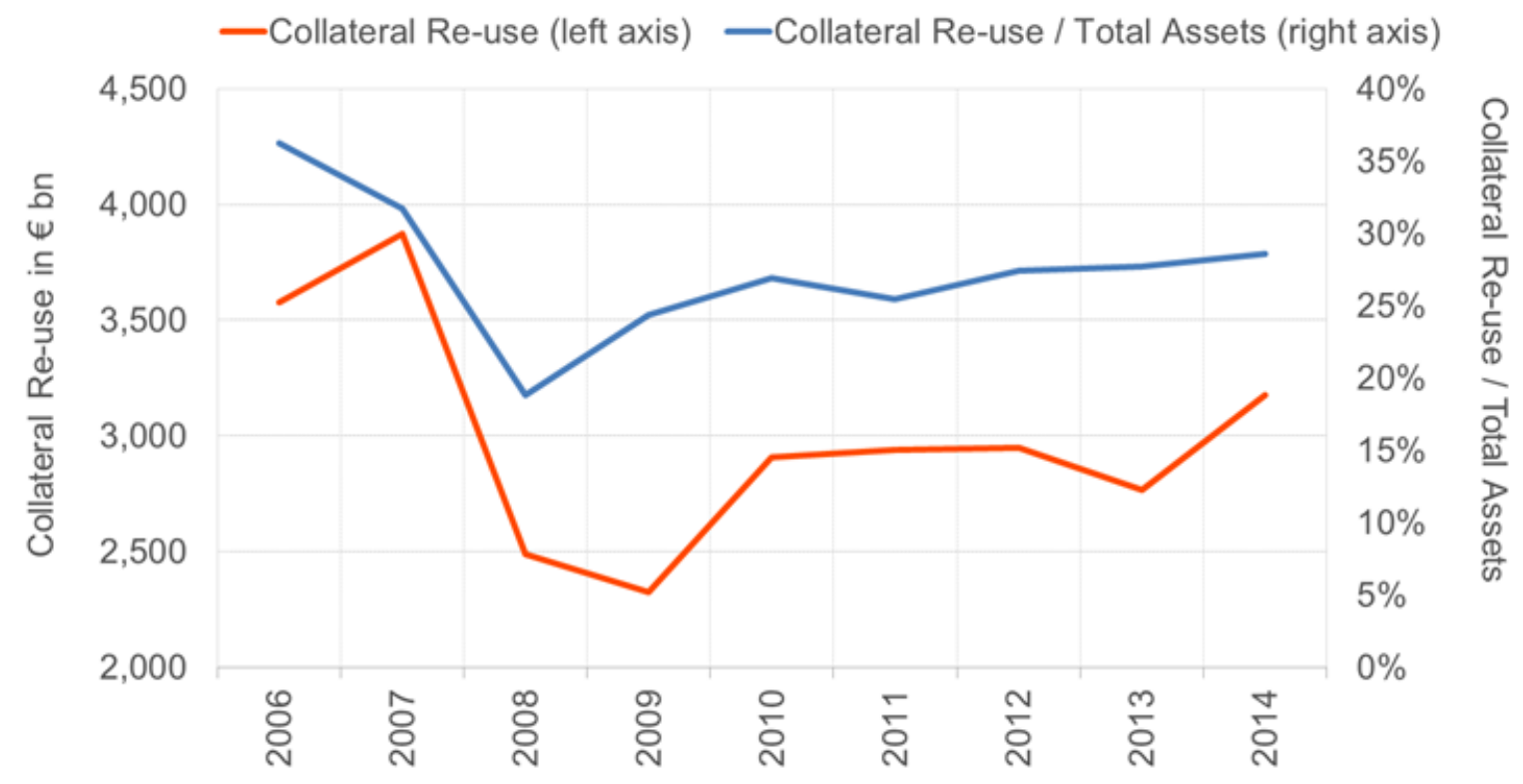

Own calculations based on 13 banks' annual reports. The institutions are Deutsche Bank, Societe Generale, BNP Paribas, Credit Suisse, UBS, Barclays, RBS, HSBC, Nomura, Morgan Stanley, Goldman Sachs, JPMorgan Chase \& Co., Citi. The figure shows collateral re-use in billion Euros and the ratio of the values of re-used collateral and total assets.

series further reveals that collateral re-use exhibits strong pro-cyclicality. The most striking fact appearing in the data is the sharp contraction in collateral re-use taking place during the global financial crisis, in 2008. Thereafter, the amount of collateral re-used by financial institutions has risen again, however, without returning to pre-crisis levels.

Figure II reports the evolution of the average re-use rate for the set of 13 global banks. The re-use rate is defined as re-used collateral divided by collateral received that is eligible for re-use. The re-use rate reflects banks' intensity of re-use. Even during the financial crisis 2007-09, the average re-use rate remained above $70 \%$.

${ }^{5}$ See Singh $(2014)$ for a similar exercise using a different methodology. 
Figure II: Collateral Re-use Rate

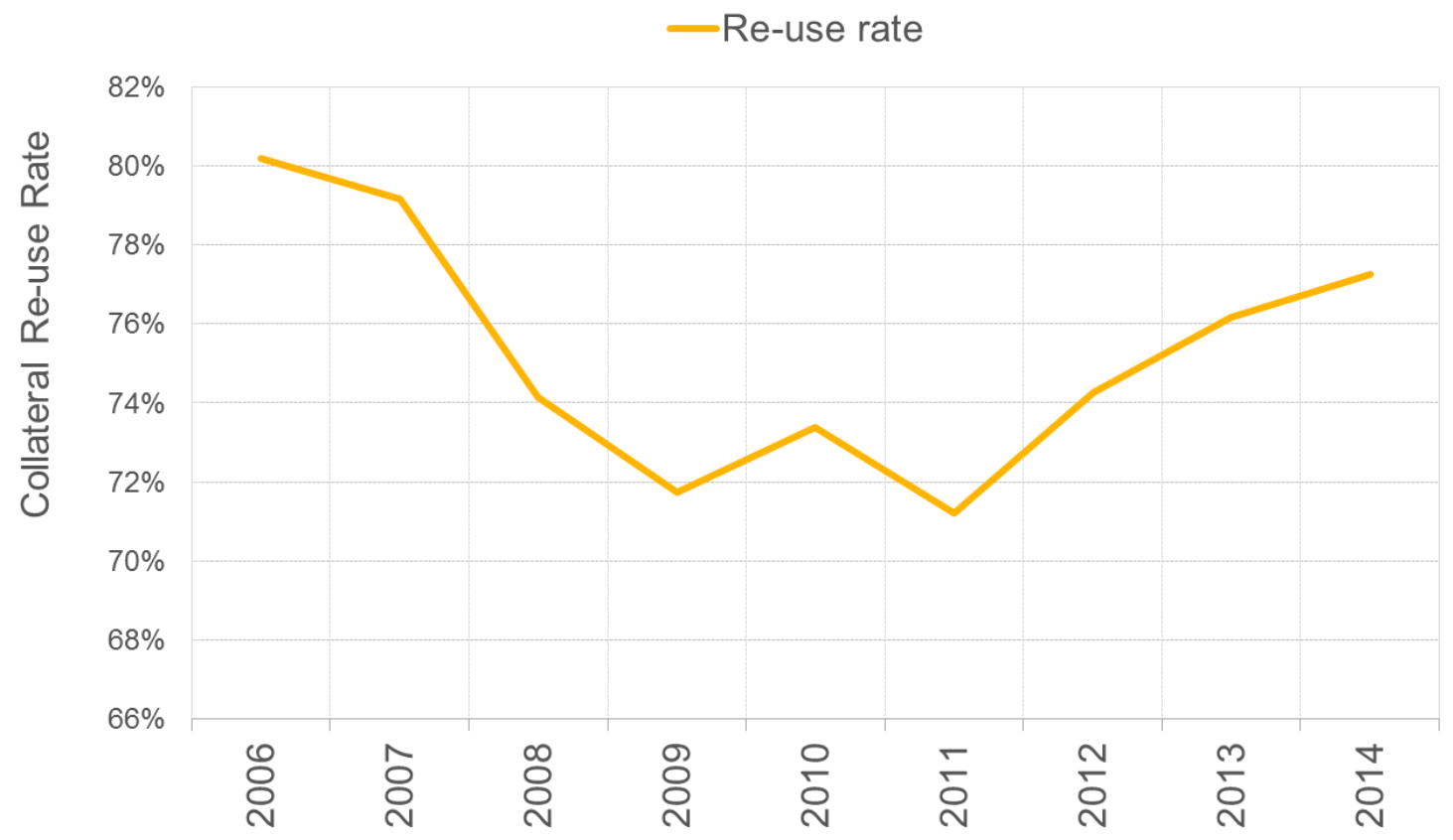

Own calculations based on 13 banks' annual reports. The institutions are Deutsche Bank, Societe Generale, BNP Paribas, Credit Suisse, UBS, Barclays, RBS, HSBC, Nomura, Morgan Stanley, Goldman Sachs, JPMorgan Chase \& Co., Citi. The figure shows the proportion of re-used collateral relative to the collateral received that is eligible for re-use. 


\subsection{Financial stability risks associated with collateral re-use}

While market participants have stressed the importance of re-use of collateral as a source of funding and market liquidity more generally, regulators and supervisors have raised various concerns about this market practice. For example, the same piece of collateral may be used to back a chain of transactions and may therefore contribute to system-wide leverage. This concern has, for example, been raised by Vice-President of the ECB, Vítor Constâncio, who stressed that "activities of rehypothecation and re-use of securities amplified the creation of chains of inside liquidity and higher leverage" 6 6 More specifically, the use of the same security as underlying collateral for different transactions increases the sum of exposures in the financial system and, and as result, creates leverage across the intermediation chain. The evidence presented in Figures $\mathrm{V}$ and II suggests that re-use practices may be significant drivers of financial system leverage. The apparent cyclical behavior of aggregate re-use activities suggests that re-use may also contribute to pro-cyclicality in the financial sector. In good times, market participants tend to be more willing to allow counterparties to re-use the collateral, increasing market liquidity and lowering the cost of capital. However, in stressed market conditions, market participants become more sensitive to counterparty risk and hence, may refuse the re-use of their collateral, amplifying strains already present in markets (see also FSB (2017b)). Moreover, FSB (2017b) highlights the issue of interconnectedness arising from chains of transactions involving the re-use of collateral. Large exposures amongst financial institutions create a risk of contagion, though it is acknowledged that securities financing transactions usually involve small net exposures because of daily margining. Nevertheless, the unwinding of a transaction by one institution may trigger the unwinding of transactions by other institutions, and lead to the propagation of shocks through the financial system. In the context of re-hypothecation it has been argued that it creates the possibility of a run on a prime-broker if there are concerns about its credit worthiness, and therefore clients have an incentive to withdraw their assets from their prime brokers $]^{7}$ This risk appears, at least to some extent, to have materialized around the failures of Bear Stearns and Lehman Brothers, where hedge funds moved their assets from their prime brokers. These actions exacerbated the financing problems faced by the two entities which had relied on the availability of client assets for the financing of their activities 8

\subsection{The regulatory framework and ongoing initiatives}

When it comes to the regulatory framework for collateral re-use, it helps to distinguish between broader re-use of collateral and the narrower set of client asset re-hypothecation. On collateral re-use more broadly, no general restrictions exist. There are however a few cases where limits or bans on re-use exist for specific entities or transactions. One example relates to retail investment

\footnotetext{
${ }^{6}$ V. Constâncio, Beyond traditional banking: a new credit system coming out of the shadows, Speech, University of Frankfurt, 17 October 2014.

${ }^{7}$ See Duffie (2010) for an extensive discussion of this issue.

${ }^{8}$ See Aragon and Strahan (2012) for an analysis of the impact the failure of Lehman Brothers had on its hedge fund clients.
} 
funds (UCITS funds) in the EU. The ESMA Guidelines on ETFs and other UCITS issues 9 require that UCITS do not re-use non-cash collateral they receive and set conditions for re-investment of cash collateral. A second example relates to initial margin posted in OTC derivatives. The EU regulatory technical standards (RTS) on margin requirements for non-centrally cleared derivatives foresees that re-use of non-cash collateral collected as initial margin shall not be permitted. Moreover, the FSB has recently published two papers related to collateral re-use. FSB (2017b) analyzes the financial stability implications of collateral re-use as well as the benefits of collateral re-use for financial markets. This paper furthermore describes a number of post-crisis regulatory reforms related both directly and indirectly to the re-use of collateral and mitigating at least some of the risks described above. While the FSB sees no need for immediate regulatory action, it considers that appropriately monitoring collateral re-use at the global level will be an important step towards obtaining a clearer understanding of global collateral re-use activities. Hence, to enhance monitoring of global collateral re-use activity, the FSB published a paper that sets out methodology for measuring non-cash collateral re-use, and describes the related data elements that national authorities would report to the FSB (see FSB (2017a)). This FSB paper further defines various metrics that could be used to monitor financial stability risks associated with collateral re-use.

To address financial stability concerns related to re-hypothecation of client assets, the FSB issued several recommendations in 2013 (see FSB (2013)). These aim at reducing client uncertainty about the extent to which assets have been re-hypothecated and the treatment in case of bankruptcy, and at limiting re-hypothecation of client assets (without an offsetting indebtedness) to financial intermediaries subject to adequate regulation of liquidity risk. Moreover, the FSB recommended that prime brokers/banks shall use that amount of client assets only that they need for the purpose of financing client activities, representing an aggregate limit on the amount of client assets they can re-hypothecate. Without this aggregate limit, prime brokers could in theory use all client assets eligible for re-hypothecation, including for their own activities and irrespective of the aggregate level of financing their set of clients requires.

With regard to existing regulatory measures on re-hypothecation, in the EU the recently agreed Securities Financing Transaction Regulation (SFTR) imposes minimum market-wide conditions to be met on re-hypothecation of client assets such as prior consent, disclosure of the risks and consequences of re-hypothecation, and transfer of the financial instruments from the account of the client. Furthermore, in the EU no aggregate nor client-individual limit on the amount of client assets available for re-hypothecation exists and is instead agreed between the two counterparties. This is in contrast to US framework where an individual limit of $140 \%$ of the clients indebtedness applies, next to an aggregate limit in line with the aforementioned FSB recommendation. However, specifically to EU investment funds, custodians of UCITs assets are prohibited from re-using (including, but not limited to, transferring, pledging, selling and lending) fund's assets for their own account according to UCITS funds (see FSB (2017a)).

\footnotetext{
${ }_{9}^{9}$ See https://www.esma.europa.eu/sites/default/files/library/2015/11/esma-2014-0011-01-00_en_0.pdf
} 


\section{The Model}

This section introduces an infinite-horizon exchange economy with two infinitely lived heterogeneous agents trading in a Lucas tree and a bond. Both assets can be traded on margin, in which case collateral needs to be posted. The received collateral can potentially be re-used. Both assets can be shorted. In case of the Lucas three, naked shorting is not possible, so an agent can only short the tree if he has received it as collateral. A regulating agency limits the extend to which collateral can be re-used.

\subsection{The Physical Economy}

Time is indexed by $t=0,1,2, \ldots$. Exogenous shocks $\left(s_{t}\right)$ follow a Markov chain with support $\mathcal{S}=\{1, \ldots, S\}$ and transition matrix $\pi$. The evolution of time and shocks in the economy is represented by an infinite event tree $\Sigma$. Each node of the tree, $\sigma \in \Sigma$, describes a finite history of shocks $\sigma=s^{t}=\left(s_{0}, s_{1}, \ldots, s_{t}\right)$ and is also called a date-event. The symbols $\sigma$ and $s^{t}$ are used interchangeably. To indicate that $s^{t^{\prime}}$ is a successor of $s^{t}$ (or is $s^{t}$ itself), write $s^{t^{\prime}} \succeq s^{t}$. The expression $s^{-1}$ refers to the initial conditions of the economy prior to $t=0$.

At each date-event $\sigma \in \Sigma$, there is a single perishable consumption good. The economy is populated by $H=2$ agents, $h \in \mathcal{H}=\{1,2\}$. Agent $h$ receives an individual endowment in the consumption good, $e^{h}(\sigma)>0$, at each node. Agent $h$ believes that the transition matrix of the Markov chain of exogenous shocks is $\pi^{h}$-this matrix may differ from the true transition matrix $\pi$. There is a single long-lived asset ("Lucas tree") in the economy, which we also call stock. At the beginning of period 0 , each agent $h$ owns initial holdings $\theta^{h}\left(s^{-1}\right) \geq 0$ of this asset. Aggregate holdings in the long-lived asset sum to one - that is, $\sum_{h \in \mathcal{H}} \theta^{h}\left(s^{-1}\right)=1$. At date-event $\sigma$, agent $h$ 's (end-of-period) holding of the asset is denoted by $\theta^{h}(\sigma)$. The long-lived asset pays positive dividends $d(\sigma)$ in units of the consumption good at all date-events. The aggregate endowments in the economy is then

$$
\bar{e}(\sigma)=d_{a}(\sigma)+\sum_{h \in \mathcal{H}} e^{h}(\sigma) .
$$

Agent $h$ has preferences over consumption streams $c^{h}=\left(c^{h}\left(s^{t}\right)\right)_{s^{t} \in \Sigma}$ representable by the following recursive utility function, see Epstein and Zin (1989),

$$
U^{h}\left(c^{h}, s^{t}\right)=\left\{\left[c^{h}\left(s^{t}\right)\right]^{\rho^{h}}+\beta\left[\sum_{s_{t+1}} \pi^{h}\left(s_{t+1} \mid s_{t}\right)\left(U^{h}\left(c^{h}, s^{t+1}\right)\right)^{\alpha^{h}}\right]^{\frac{\rho^{h}}{\alpha^{h}}}\right\}^{\frac{1}{\rho^{h}}}
$$

where $\frac{1}{1-\rho^{h}}$ represents the intertemporal elasticity of substitution (IES) and $1-\alpha^{h}$ the relative risk aversion of the agent.

\subsection{Financial Markets and Collateral}

At each date-event, agents can engage in security trading of two assets, long-lived stocks and oneperiod bonds. Agent $h$ can buy $\theta^{h}(\sigma)$ shares of the long-lived asset at node $\sigma$ for a price $q(\sigma)$. 
Importantly, agents can short-sell long-lived assets. We assume that short positions in the long-lived asset cannot be "naked", meaning that agents must cover their short sales by having borrowed the long-lived asset.10 In addition to the long-lived asset, there is a single one-period bond available for trade; this bond is in zero net supply and its face value is one unit of the consumption good in the subsequent period. Agent $h$ 's (end-of-period) holding of this bond at date-event $\sigma$ is denoted by $\phi^{h}(\sigma)$, and the price of the bond at this date-event by $p(\sigma)$. Agents can also take up debt by shorting this bond.

The agents can default on short positions in the long-lived asset or the short-lived bond at any time without any utility penalties or loss of reputation. Therefore, to enter a short position in either one of the two assets, agents must back up their promised payments by collateral. Since there are only two assets in the economy, an agent who borrows by assuming a short position in the long-lived asset must hold a long position in the bond as collateral. And vice versa, an agent who shorts the bond must hold a long position of the long-lived asset as collateral.

Specifically, if an agent borrows by short-selling the stock, $\theta^{h}\left(s^{t}\right)<0$, then that agent is required to hold a sufficient amount of collateral in the bond. The difference between the value of the collateral holding in the bond, $p\left(s^{t}\right) \phi^{h}\left(s^{t}\right)>0$, and the current value of the loan, $-q\left(s^{t}\right) \theta^{h}\left(s^{t}\right)$, is the amount of capital the agent puts up to obtain the loan. A margin requirement, $m_{s}\left(s^{t}\right) \in[0,1]$, enforces a lower bound on the value of this capital relative to the value of the collateral,

$$
m_{s}\left(s^{t}\right)\left(p\left(s^{t}\right) \phi^{h}\left(s^{t}\right)\right) \leq q\left(s^{t}\right) \theta^{h}\left(s^{t}\right)+p\left(s^{t}\right) \phi^{h}\left(s^{t}\right) .
$$

Similarly, if an agent borrows by short-selling the bond, $\phi^{h}\left(s^{t}\right)<0$, then that agent is required to hold a sufficient amount of collateral in the long-lived asset. The difference between the value of the collateral holding in the long-lived asset, $q\left(s^{t}\right) \theta^{h}\left(s^{t}\right)>0$, and the current value of the loan, $-p\left(s^{t}\right) \phi^{h}\left(s^{t}\right)$, is the amount of capital the agent puts up to obtain the loan. A margin requirement, $m_{l}\left(s^{t}\right) \in[0,1]$, enforces a lower bound on the value of this capital relative to the value of the collateral,

$$
m_{l}\left(s^{t}\right)\left(q\left(s^{t}\right) \theta^{h}\left(s^{t}\right)\right) \leq q\left(s^{t}\right) \theta^{h}\left(s^{t}\right)+p\left(s^{t}\right) \phi^{h}\left(s^{t}\right) .
$$

Since there are no penalties for default, an agent who sold the stock at date-event $s^{t}$ defaults on his or her promise at a successor node $s^{t+1}$ whenever the initial promise exceeds the current value of the collateral - that is, whenever

$$
-\theta^{h}\left(s^{t}\right)\left(q\left(s^{t+1}\right)+d\left(s^{t+1}\right)\right)>\phi^{h}\left(s^{t}\right) .
$$

Similarly, an agent who sold the bond at date-event $s^{t}$ defaults on his or her promise at a successor node $s^{t+1}$ whenever the initial promise exceeds the current value of the collateral - that is, whenever

$$
-\phi^{h}\left(s^{t}\right)>\theta^{h}\left(s^{t}\right)\left(q\left(s^{t+1}\right)+d\left(s^{t+1}\right)\right) .
$$

In this paper, margin requirements are sufficiently large so that no default occurs in equilibrium and defaultable bonds are not traded. In Brumm et al. (2015) this restriction is an equilibrium outcome:

${ }^{10}$ Note that this assumption is in line with short selling regulations in the EU and the US (see, e.g., https://www.esma. europa.eu/regulation/trading/short-selling) 
following Geanakoplos (1997) and Geanakoplos and Zame (2002), Brumm et al. (2015) assume that, in principle, bonds with any margin requirement may be traded in equilibrium, yet show that with moderate default costs only risk-free bonds are traded.

We consider two different rules for the determination of margin requirements. According to the first rule, financial markets determine margin requirements, $m_{s}\left(s^{t}\right)$ and $m_{l}\left(s^{t}\right)$, that are just large enough to prevent default in equilibrium. Specifically, for borrowing with the long-lived asset against the bond, market-determined margin requirements $m_{s}\left(s^{t}\right)$ are the lowest possible margins that still ensure no default in the subsequent period,

$$
m_{s}\left(s^{t}\right)=1-\frac{q\left(s^{t}\right)}{\max _{s_{t+1}}\left\{q\left(s^{t+1}\right)+d\left(s^{t+1}\right)\right\} p\left(s^{t}\right)} .
$$

Substituting this margin requirement into inequality (1) leads to the inequality

$$
-\theta^{h}\left(s^{t}\right) \max _{s_{t+1}}\left\{q\left(s^{t+1}\right)+d\left(s^{t+1}\right)\right\} \leq \phi^{h}\left(s^{t}\right) .
$$

Similarly, for borrowing with the bond against the long-lived asset, market-determined margin requirements $m_{l}\left(s^{t}\right)$ are the lowest possible margins that still ensure no default in the subsequent period,

$$
m_{l}\left(s^{t}\right)=1-\frac{p\left(s^{t}\right) \cdot \min _{s_{t+1}}\left\{q\left(s^{t+1}\right)+d\left(s^{t+1}\right)\right\}}{q\left(s^{t}\right)} .
$$

Substituting this margin requirement into inequality (2) leads to the inequality

$$
-\phi^{h}\left(s^{t}\right) \leq \theta^{h}\left(s^{t}\right) \min _{s_{t+1}}\left\{q\left(s^{t+1}\right)+d\left(s^{t+1}\right)\right\} .
$$

This margin requirement makes the bond risk-free by ensuring that a short-seller will never default on his or her promise.

According to the second rule, a (not further modeled) regulating agency requires debtors to have a certain minimal amount of capital relative to the value of the collateral they hold. Put differently, the regulator imposes a floor on margin requirements so that the margin requirements for regulated assets traded is always the larger of this required minimal level $m_{s}^{r}(\sigma)$ (or $m_{l}^{r}(\sigma)$ ) and the marketdetermined margin level $m_{s}(\sigma)$ (or $m_{l}(\sigma)$ ). If the minimal levels are one, then no asset can be used as collateral.

\subsection{Re-use of Collateral}

In our economy, when collateral is posted, the agent receiving it has the right to re-use the collateral for his own purposes, either using it as collateral for another transaction or (short-)selling it 11 We denote the amount of collateral received by agent $h$ by $\theta_{\text {received }}^{h}\left(s^{t}\right)$, and the amount of collateral re-used by $\theta_{\text {reused }}^{h}\left(s^{t}\right)$. We furthermore assume that a regulatory agency can set a limit $\kappa\left(s^{t}\right) \in[0,1]$

\footnotetext{
${ }^{11}$ In financial markets, a significant amount of collateral is supplied including a transfer of title (e.g., in repo transactions) that implies that for the length of the transaction the counterparty receiving the collateral becomes the owner of the collateral. It is, therefore, free to use it as collateral in a different transaction or to sell it.
} 
on the fraction of the received collateral that can be re-used by agents. This leads to the following re-use constraint for agent $h$ :

$$
\theta_{\text {reused }}^{h}\left(s^{t}\right) \leq \kappa\left(s^{t}\right) \cdot \theta_{\text {received }}^{h}\left(s^{t}\right)
$$

Note that, given the assumption that naked shorting is ruled out in our framework, allowing for re-use only renders possible short-sales in the long-lived asset. Setting the re-use parameter $\rho\left(s^{t}\right)$ equal to zero would lead to a situation where not only re-use is ruled out but also short selling is banned completely. Using the collateral constraint (2) and the re-use constraint (3) we can now determine the maximum short position agents can assume. First of all, we need to determine how much collateral agent $h$ receives, $\theta_{\text {received }}^{h}\left(s^{t}\right)$. The collateral constraint (2) that the other agent, $-h$, faces for a short position in the bond dictates how much collateral agent -h has to post and thus how much agent $h$ receives:

$$
\theta^{-h}\left(s^{t}\right) \geq \frac{p\left(s^{t}\right) \cdot \max \left\{0,-\phi^{-h}\left(s^{t}\right)\right\}}{\left(1-m_{l}\left(s^{t}\right)\right) q\left(s^{t}\right)}=\theta_{\text {received }}^{h}\left(s^{t}\right) .
$$

The lender, agent $h$, can reuse a portion $\rho\left(s^{t}\right)$ of this collateral for his own purposes. If he uses it for short-selling, we have $-\theta^{h}\left(s^{t}\right)=\theta_{\text {reused }}^{h}\left(s^{t}\right)$. Using (3) and (4), we obtain a lower bound on the position of agent $h$ in the long-lived asset,

$$
\theta^{h}\left(s^{t}\right) \geq-\kappa\left(s^{t}\right) \frac{p\left(s^{t}\right) \max \left\{0,-\phi^{-h}\left(s^{t}\right)\right\}}{\left(1-m_{l}\left(s^{t}\right)\right) q\left(s^{t}\right)} .
$$

Observe that for $\phi^{-h}\left(s^{t}\right)<0$ obviously $\phi^{h}\left(s^{t}\right)>0$; the lower bound is negative and agent $h$ is permitted to short the long-lived asset. Essentially he sells a portion of the collateral owned by agent $-h$ but pledged to him. Note that the re-use constraint (5) is also valid for $\phi^{h}\left(s^{t}\right) \leq 0$ and then reduces to $\theta^{h}\left(s^{t}\right) \geq 0$. If the agent does not own collateral in the short-lived bond, then he cannot short the long-lived asset.

\subsection{Financial Markets Equilibrium with Collateral}

We are now in the position to formally define a financial markets equilibrium. Equilibrium values of a variable $x$ are denoted by $\bar{x}$.

DEFINITION 1 A financial markets equilibrium for an economy with regulated re-use limits, $(\kappa(\sigma))_{\sigma \in \Sigma}$, regulated minimum margins $\left(m_{l}^{r}(\sigma), m_{s}^{r}(\sigma)\right)_{\sigma \in \Sigma}$, initial shock $s_{0}$, and initial asset holdings $\left(\theta^{h}\left(s^{-1}\right)\right)_{h \in \mathcal{H}}$ is a collection of agents' portfolio holdings and consumption allocations as well as security prices and margin requirements, $\left(\left(\bar{\theta}^{h}(\sigma), \bar{\phi}^{h}(\sigma), \bar{c}^{h}(\sigma)\right)_{h \in \mathcal{H}} ; \bar{q}(\sigma), \bar{p}(\sigma) ; \bar{m}_{l}(\sigma), \bar{m}_{s}(\sigma)\right)_{\sigma \in \Sigma}$, satisfying the following conditions:

(1) Markets clear:

$$
\sum_{h \in \mathcal{H}} \bar{\theta}^{h}(\sigma)=1 \quad \text { and } \quad \sum_{h \in \mathcal{H}} \bar{\phi}^{h}(\sigma)=0 \quad \text { for all } \sigma \in \Sigma .
$$


(2) For each agent $h$, the choices $\left(\bar{\theta}^{h}(\sigma), \bar{\phi}^{h}(\sigma), \bar{c}^{h}(\sigma)\right)$ solve the agent's utility maximization problem,

$$
\begin{aligned}
\max _{\theta \geq 0, \phi, c \geq 0} U_{h}(c) & \text { s.t. } \quad \text { for all } s^{t} \in \Sigma \\
c\left(s^{t}\right)+\theta^{h}\left(s^{t}\right) \bar{q}\left(s^{t}\right)+\phi^{h}\left(s^{t}\right) \bar{p}\left(s^{t}\right) & =e^{h}\left(s^{t}\right)+\phi\left(s^{t-1}\right)+\theta^{h}\left(s^{t-1}\right)\left(\bar{q}\left(s^{t}\right)+d\left(s^{t}\right)\right), \\
\bar{m}_{l}\left(s^{t}\right) \bar{q}\left(s^{t}\right) \theta^{h}\left(s^{t}\right) & \leq \bar{q}\left(s^{t}\right) \theta^{h}\left(s^{t}\right)+\bar{p}\left(s^{t}\right) \phi^{h}\left(s^{t}\right), \\
\bar{m}_{s}\left(s^{t}\right) \bar{p}\left(s^{t}\right) \phi^{h}\left(s^{t}\right) & \leq \bar{q}\left(s^{t}\right) \theta^{h}\left(s^{t}\right)+\bar{p}\left(s^{t}\right) \phi^{h}\left(s^{t}\right), \\
\theta^{h}\left(s^{t}\right) \bar{q}\left(s^{t}\right)\left(1-m_{l}\left(s^{t}\right)\right) & \geq-\kappa\left(s^{t}\right) \cdot \bar{p}\left(s^{t}\right) \max \left\{0,-\bar{\phi}^{-h}\left(s^{t}\right)\right\} .
\end{aligned}
$$

(3) For all $s^{t}$, the margin requirements satisfy

$$
\begin{aligned}
& \bar{m}_{l}\left(s^{t}\right)=\max \left\{m_{l}^{r}\left(s^{t}\right), 1-\frac{\bar{p}\left(s^{t}\right) \cdot \min _{s_{t+1}}\left\{\bar{q}\left(s^{t+1}\right)+d\left(s^{t+1}\right\}\right.}{\bar{q}\left(s^{t}\right)}\right\}, \\
& \bar{m}_{s}\left(s^{t}\right)=\max \left\{m_{s}^{r}\left(s^{t}\right), 1-\frac{q\left(s^{t}\right)}{\max _{s_{t+1}}\left\{q\left(s^{t+1}\right)+d\left(s^{t+1}\right)\right\} p\left(s^{t}\right)}\right\} .
\end{aligned}
$$

Note that long (or short) margin requirements are called unregulated if the regulated minimum margin requirement, $m_{l}(\sigma)$ (or $m_{s}(\sigma)$ ), is equal to zero for all date-events $\sigma \in \Sigma$.

\subsection{The Calibration}

We consider a growth economy with stochastic growth rates. The aggregate endowment at date-event $s^{t}$ grows at the stochastic rate $g\left(s_{t+1}\right)$ which only depends on the new shock $s_{t+1} \in \mathcal{S}$, thus

$$
\frac{\bar{e}\left(s^{t+1}\right)}{\bar{e}\left(s^{t}\right)}=g\left(s_{t+1}\right)
$$

for all date-events $s^{t} \in \Sigma$. There are four different realizations for $g\left(s_{t}\right)$. We declare the first to be a "disaster". We calibrate the disaster shock based on data from Barro and Ursúa (2008). A disaster is defined as a drop in aggregate consumption of more than 15 percent, which has a probability of 0.022 and an average size of 28 percent (see Table 10 in Barro and Ursúa (2008)). Following Barro (2009)), we choose transition probabilities such that the four exogenous shocks are i.i.d. The nondisaster shocks are then calibrated such that their average growth rate is 2 percent and their standard deviation matches the data on typical business cycle fluctuations which have a standard deviation of about 2 percent. Table 1 provides the resulting growth rates and their probabilities. Because of their respective size, we call these realizations as follows: disaster, recession, normal times, and boom.

Table I: Growth rates and their probabilities

\begin{tabular}{|c|c|c|c|c|}
\hline & Disaster & Recession & Normal Times & Boom \\
\hline growth rate $g$ & 0.72 & 0.96 & 1.02 & 1.08 \\
\hline probability $\pi(g)$ & 0.022 & 0.054 & 0.870 & 0.054 \\
\hline
\end{tabular}


We assume that agents (agree to) disagree about the probability distribution of these growth rates. The agents' beliefs deviate from the objective probabilities in opposite directions, agent 1 being optimistic and agent 2 being pessimistic. Agent 1 believes that the probability of a disaster is only $\left(1-\delta^{d}\right)$ times its objective probability. The remaining probability weight is distributed among the other growth realizations according to their objective probability weights. In addition, agent 1 underestimates the probability of a recession and overestimates the probability of a boom; these probabilities are scaled by $\left(1-\delta^{n}\right)$ and $\left(1+\delta^{n}\right)$, respectively. For the baseline calibration, we choose $\delta^{d}=\delta^{n}=0.4$.

We assume that the Lucas tree pays dividends which are, for simplicity, proportional to aggregate endowments, $d_{a}\left(s^{t}\right)=\mathfrak{d} \bar{e}\left(s^{t}\right), \mathfrak{d} \geq 0$. In our baseline calibration, the dividend share is 10 percent, i.e. $\mathfrak{d}=0.10$ - roughly equal to the value of dividends relative to the total income of stockholders in the US.

There are $H=2$ agents in the economy. Recall that the agents have recursive utility functions Epstein and Zin (1989)) with parameters $\rho^{h}$ and $\alpha^{h}$ where $1 /\left(1-\rho^{h}\right)$ is the inter-temporal elasticity of substitution (IES) and $1-\alpha^{h}$ determines the relative risk aversion of the agent. Following Barro (2009) we assume that both agents have an identical IES of 1.5. However, we assume that the two agents differ in their risk aversion. In the baseline case we set the risk aversion of agent 1 to 2 , i.e. $\alpha^{1}=-1$ and the risk aversion of agent 2 to 4 , i.e. $\alpha^{2}=-3$. We set $\beta=0.975$ to generate a real interest rate of 1.5 percent for the economy with free re-use (parameter $\kappa\left(s^{t}\right)=1$ ).

Both agents $h$ receive the same share of aggregate endowments as individual (labor) income. We abstract from idiosyncratic income shocks because it is difficult to disentangle idiosyncratic and aggregate shocks in a model with only two types of agents. Each agent $h$ 's labor income is, then, given by

$$
e^{h}\left(s^{t}\right)=0.5\left(\bar{e}\left(s^{t}\right)-d\left(s^{t}\right)\right)=0.45 \bar{e}\left(s^{t}\right) .
$$

\section{The Impact of Re-use on Leverage and Volatility}

We begin with a description how introducing the re-use of collateral into our framework affects asset pricing moments and other key economic variables in the model. For this purpose, we compare the outcome of an economy where re-use is subject to no constraints $(\kappa=1)$ to an economy in which re-use is banned entirely $(\kappa=0)$, and two economies with intermediate levels of re-use $(\kappa=0.2$ and $\kappa=0.4)$. Table II reports simulation statistics for these four economies 12 Throughout the paper we measure volatility by the standard deviation (STD) over a long horizon. The first set of results are statistics on market returns and the stock price. Next, the table displays moments for agent 1's wealth share. And the last two rows of Table II report some average characteristics of the first agent's portfolio.

We begin with some simple observations. All eight reported statistics are monotone in the re-use parameter $\kappa$. Both the average excess return and its volatility are increasing while the average risk-

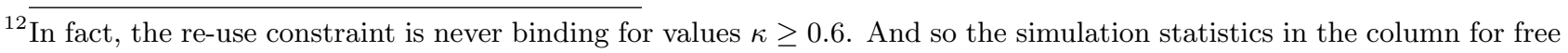
re-use $(\kappa=1)$ apply for all $\kappa \in[0.6,1]$. 
Table II: Simulation statistics for the model without re-use and with re-use

\begin{tabular}{|l|c|c|c|c|}
\hline & no re-use $(\kappa=0)$ & $\kappa=0.2$ & $\kappa=0.4$ & free re-use $(\kappa=1)$ \\
\hline mean excess return (in \%) & 0.32 & 0.45 & 0.70 & 1.1 \\
mean risk-free rate (in \%) & 2.6 & 2.3 & 2.0 & 1.5 \\
STD risky returns (in \%) & 4.5 & 4.7 & 5.1 & 6.8 \\
mean stock price & 6.3 & 6.9 & 7.6 & 8.4 \\
\hline mean wealth, agent 1 (in \%) & 34.8 & 42.5 & 55.8 & 74.6 \\
STD wealth, agent 1 (in \%) & 0.7 & 1.1 & 2.0 & 4.8 \\
\hline mean re-use rate (in \%) & 0 & 18.4 & 36.4 & 48.7 \\
mean bond holding, agent 1 & -4.1 & -5.3 & -7.0 & -8.4 \\
\hline
\end{tabular}

The table reports simulation statistics for our economic model for four different values of the re-use parameter $\kappa$. The abbreviation 'STD' stands for 'standard deviation'.

free rate is decreasing in the re-use parameter. The average stock price is increasing in $\kappa$ and so the resulting average stock return is decreasing. The more re-use is permitted in the economy, the larger are the average and the volatility of the wealth share of agent 1 . Not surprisingly, the average re-use rate, defined as re-used collateral divided by collateral received that is eligible for re-use, increases strongly with the re-use parameter; agent 1 holds, on average, a much larger short position in the bond as $\kappa$ increases.

To obtain a clear understanding of the documented reaction of the simulation statistics in response to changes in the re-use parameter $\kappa$, we next work out the economic mechanism driving the wealth and asset pricing dynamics in the economy. The agent with the low risk aversion parameter and optimistic beliefs (agent 1) is the natural buyer of risky assets and takes up leverage to finance these investments. The agent with the high risk aversion and pessimistic beliefs (agent 2) has a strong desire to insure against bad shocks and is thus willing to provide financing to the other agent backed by collateral. This model set-up is clearly visible in the two policy functions in the bottom row of Figure III. For all possible values of the endogenous state variable (the wealth share of agent 1), agent 1 holds a long position in the risky stock and a short position in the riskless bond. This portfolio structure is present for all possible values of the re-use parameter. The policy functions also clearly show the impact of the re-use parameter on the agents' portfolio positions. In the economy without re-use $(\kappa=0)$ agent 1's stock position is bounded above by the aggregate supply of one share. Once his wealth share increases above 0.2 , he holds the entire stock; his short position in the bond is then decreasing in his wealth share. If re-use is permitted, then agent 1's stock position is no longer bounded above by the aggregate supply. For positive values of $\kappa$, agent 2 can now re-use the collateral (the stock), which she receives for lending to agent 1 via her bond purchases; that is, agent 2 sells a portion of the collateral to agent 1. As a result, agent 1's position now exceeds the aggregate supply of one share. This agent finances the additional stock purchases with further borrowing in the bond. Thus, his short position in the bond now becomes much larger than in the 
Figure III: Price and policy functions
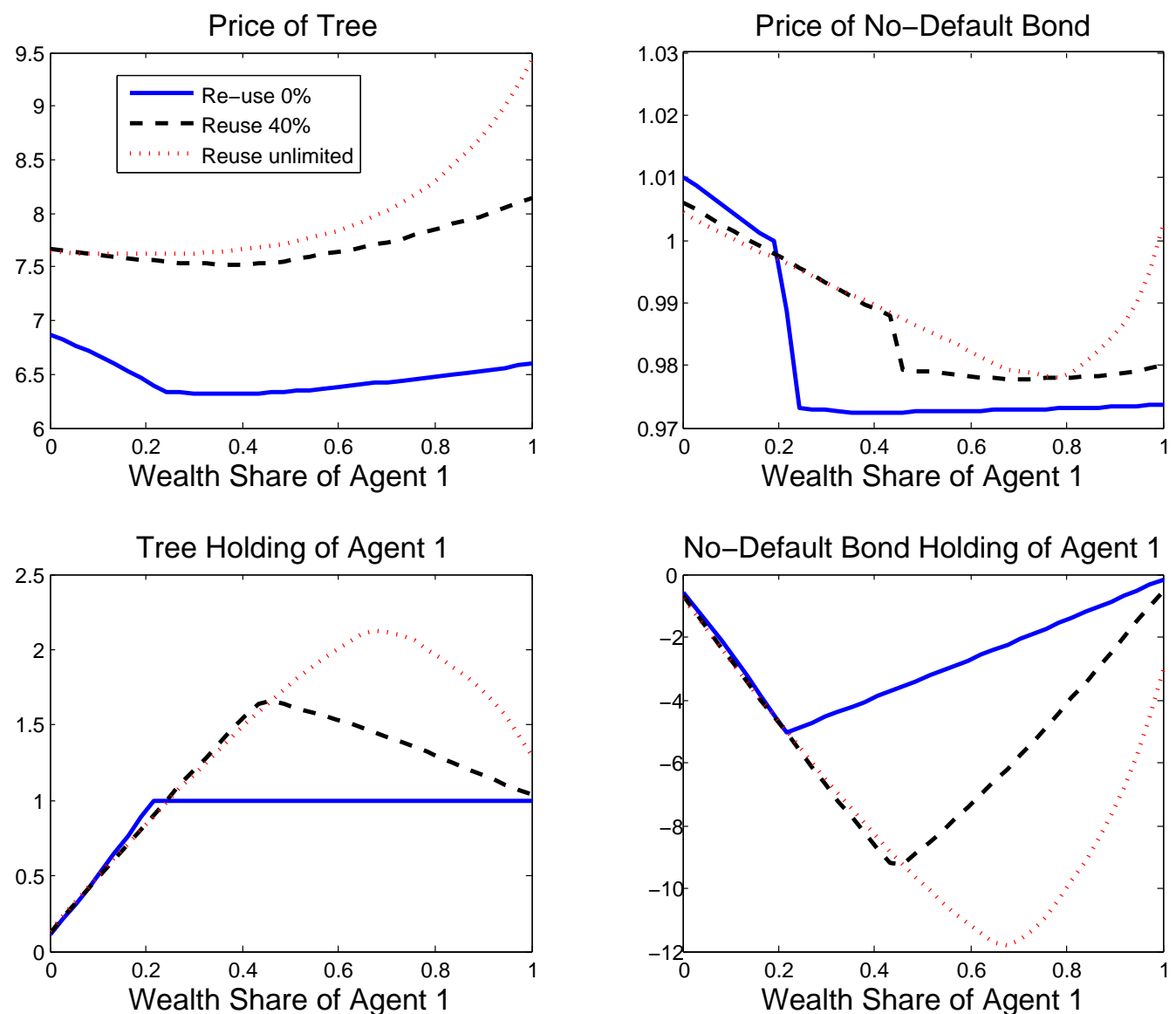

The top row of graphs shows the prices of the stock and the bond as functions of the wealth share of agent 1 . The bottom row displays agent 1's portfolio holdings as a function of his wealth share. 
economy without re-use.

To understand the non-monotone behavior of the policy functions, we next turn to the constraints in the agents' utility maximization problems; two constraints play important roles in equilibrium. Figure IV] displays the slack in the long margin constraint of agent 1 and in the re-use constraint of agent 2 for the economy without re-use (panel (a)) and for the economy with limited re-use, $\kappa=0.4$ (panel (b)). In the economy without reuse, $\kappa=0$, the re-use constraint (3) becomes a short-selling

Figure IV: Slack in constraints

(a) $\kappa=0$

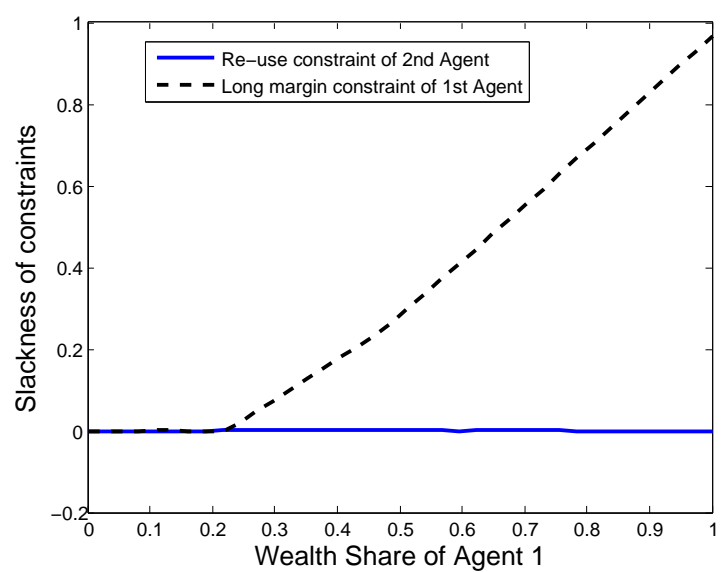

(b) $\kappa=0.4$

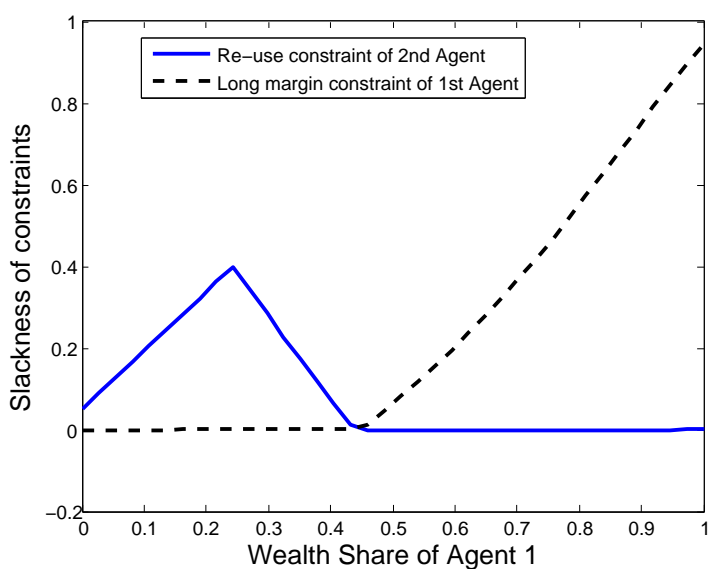

The figure shows the slack in the re-use constraint (3) of agent 2 and the long margin constraint (2) of agent 1 , respectively. For $\kappa=0$ agent 1's re-use constraint (3) reduces to $\theta_{\text {reused }}^{h}\left(s^{t}\right) \leq 0$ and so the slack is trivially zero on the entire state space.

constraint, $\theta^{2}\left(s^{t}\right) \geq 0$, and is binding for agent 2 , whenever agent 1 holds the entire stock, which is the case whenever the wealth share of agent 1 exceeds a threshold of about 0.22 , see also Figure III. As agent 1's wealth share increases for levels above 0.22 , he cannot buy more of the stock but only reduce his debt in the bond. Therefore, his long margin constraint (2) is not binding in this region of the state space. On the contrary, when agent 1 has a wealth share below the threshold of 0.22 , he buys as much stock as permissible under the long margin constraint (2) and so this constraint is binding.

In the economy with limited re-use, $\kappa=0.4$, the long margin constraint of agent 1 is binding when his wealth share is below a threshold of 0.45 . In this region of the state space, agent 1 buys as many shares of the stock as permissible under the long margin constraint (2). For wealth shares above this threshold, the re-use constraint of agent 2 becomes binding and then agent 1 can no longer increase his stock holding. As agent 1's wealth share increases for levels above 0.45 , he can only reduce his debt in the bond, see again the bottom row of Figure III. But then the re-use constraint (3) forces agent 2 to use less re-use, which, in turn, means that agent 1 must reduce his long stock position and instead reduce his bond debt even further. Agent 1's bond holding function in Figure III shows that it increases steeply in the region above the threshold. 
As a result of the two key constraints, leverage peaks at the wealth share where both constraints are binding. These threshold points lead to the global minima of agent 1's bond holding function in Figure III. As agent 1's wealth share increases beyond these points, his long position in the stock and his short position in the bond become decreasing in the endogenous state variable. In light of these equilibrium portfolios of the two agents, it is clear that both the mean re-use rate and the average bond positions (in absolute value) of each agent are increasing in the re-use parameter $\kappa$, see again Table II. The observed changes in the equilibrium portfolio functions for increasing values of $\kappa$ have a strong impact on the wealth distribution. The less risk-averse and more optimistic agent 1 holds the dividend-paying stock (most of the time). Both his average stock holding function and the average excess return are increasing in $\kappa$. Therefore, his wealth share is also increasing in $\kappa$. Table II reports that agent 1's average wealth share grows from about one-third in the economy without re-use to almost three-quarters in the economy with unlimited re-use.

Next we take a look at equilibrium dynamics. Figure $[\mathrm{V}$ shows simulated paths of key economic variables for an economy with unconstrained re-use, $\kappa=1$. Observe that re-use is positive for the vast majority of periods and agent 1 has considerable debt (via his short position in the bond). When the economy is now hit by a disaster shock, the leveraged agent 1 loses financial wealth. In the simulation in Figure V, disaster shocks occurred in periods 22, 33, 69, and 84. Each time agent 1 's wealth share drops dramatically to values well below 0.5 . As a result, the long margin constraint becomes binding and forces him to reduce consumption, to reduce his stock holding, and to reduce his short position in the bond.

In light of these implication of a negative shock, Table II shows, not surprisingly, that the volatility of agent 1's wealth share increases considerably in the re-use parameter $\kappa$. Hence, introducing re-use of collateral into the model leads to significantly larger movements in the wealth distribution of the economy. More collateral becomes available in financial markets, allowing agents to drastically increase leverage in comparison to an economy without re-use.

The stock price function, see Figure III, becomes steeper around the average wealth share of agent 1 as the re-use parameter $\kappa$ increases. Therefore, the enlarged volatility in the endogenous state variable now also leads to an increase in the stock price volatility. We observe this effect in Table II: the standard deviation of the equity excess returns is increasing in $\kappa$. Figure VI, which plots the stock return volatility as a function of the re-use parameter, provides additional information. We observe that the stock return volatility increases monotonically as the re-use parameter increases. Once the re-use parameter is reaching a value of about $60 \%$, the re-use constraint is never binding along simulated equilibrium paths; hence, any further relaxation of the constraint does not affect the stock's return volatility.

Finally, we turn to the levels of the asset prices. Table II and Figure III show that not only the average prices of both assets increase in the re-use parameter $\kappa$ but that the functions increase, particularly around the average values of the state variable. At first, particularly the increase in the stock price as a function of the re-use parameter may appear surprising since with $\kappa$ also the amount of available collateral increases. This price increase is a consequence of the increased bond price. Due to the smaller interest rate the future dividends of the stock become more valuable and so the 
Figure V: Simulated paths of equilibrium quantities
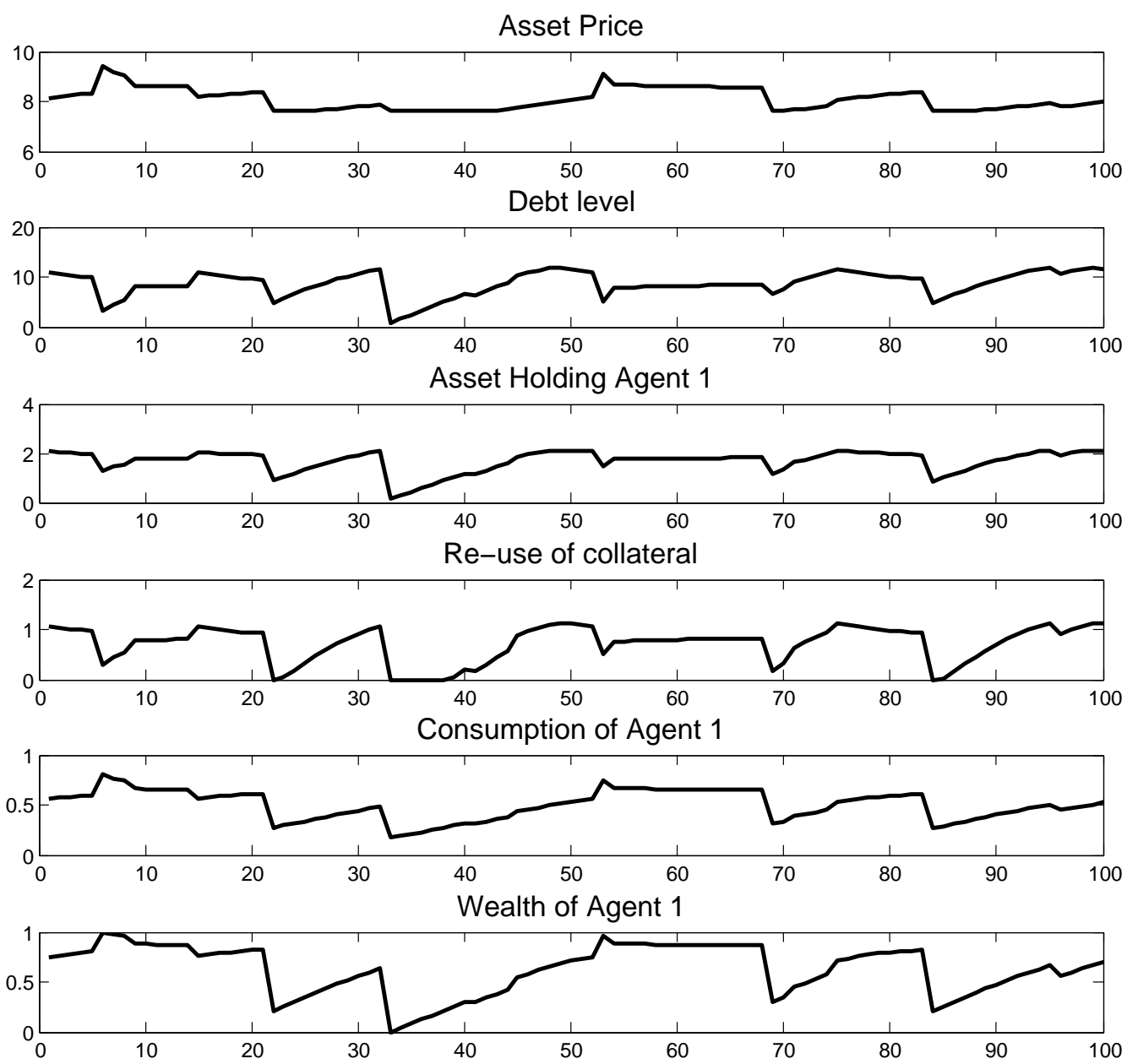

The figure shows simulated paths of six different equilibrium quantities over 100 periods. Disaster shocks occurred in periods 22, 33, 69, and 84. The graph on re-use of collateral shows a path of agent 2's short-position in the stock, which is identical to $\max \left(0, \theta^{1}\left(s^{t}\right)-1\right)$. 
Figure VI: Stock return volatility as a function of the re-use parameter

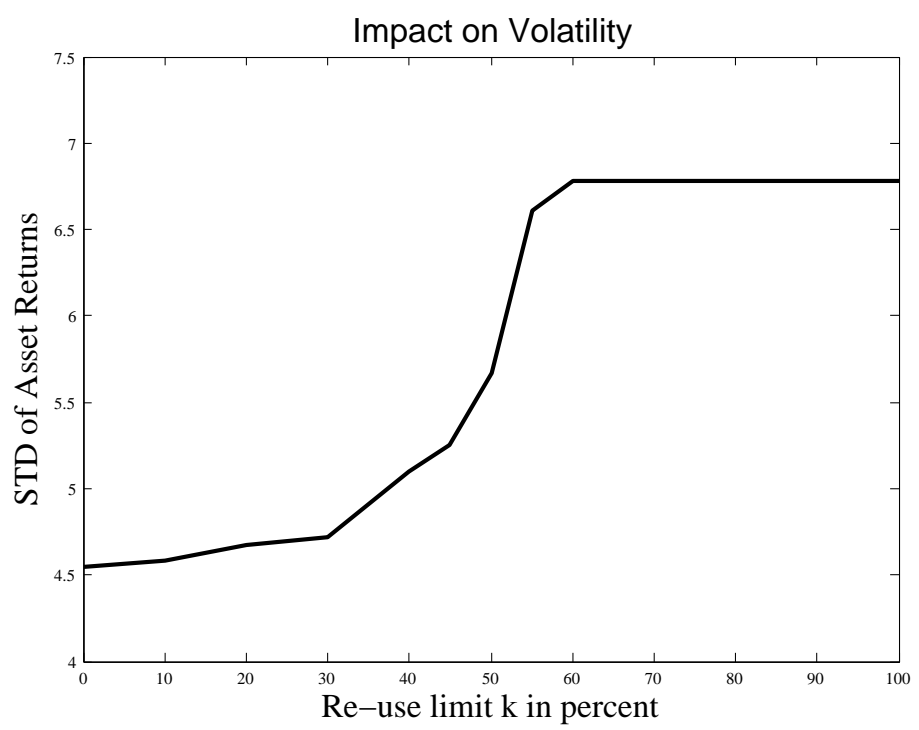

The graph shows the volatility of the stock return as a function of the re-use parameter $\kappa$.

stock prices increases. There are two reasons for the increase in the bond price. First, increased re-use results in more risk-sharing for the two agents. In particular, agent 2 can insure herself against negative shocks much better through much larger holdings of the riskless bond. For example, this agent's average stock and bond holdings are $(0.02,4.1)$ for $\kappa=0$ and $(-0.73,8.4)$ for $\kappa=1$. For such more desirable portfolios, agents demand a lower (objective) return. Therefore, the risk free rate falls from $2.6 \%$ to $1.5 \%$ and the stock return from $2.9 \%$ to $2.6 \%$ (despite a higher standard deviation) as we compare an economy with $\kappa=0$ to one with $\kappa=1$. The lower average return implies, of course, a higher average price of the risky asset. Second, increased re-use makes the bond more valuable to agent 2 - that is, the bond has an increasing collateral value, see Fostel and Geanakoplos (2008). This increasing collateral value increases the price of the bond.

\section{$5 \quad$ Welfare Implications of Re-use Limits}

Next we analyze the impact of re-use limits on the agents' welfare. For this, we first have to take a stand on how to measure welfare in the presence of heterogeneous beliefs. One can take the extreme position that probabilities are part of a mathematical representation of preferences but have no meaning outside the context of this representation and even question the existence of objective probabilities. In this case regulation of re-use will always make everybody worse off. On the other hand, as Gilboa et al. (2014) point out, "Savage's (1954) derivation of subjective expected utility maximization takes only preferences between acts as its point of departure, but his development is compatible with a view of probabilities as ranking events by their likelihood. Similarly, his development is consistent with a view of probabilities and utilities as conceptually different. The view that probabilities are not empty, theoretical constructs runs throughout economics." There are now 
several alternative definitions of Pareto-optimality under differences in beliefs (see e.g. Brunnermeier et al. (2014), Gilboa et al. (2014) and the references therein). Following Brunnermeier et al. (2014), we say that an allocation A is Pareto-better than allocation B if under all beliefs in the convex hull of agents' subjective probabilities the allocation makes both agents better off (perhaps after a redistribution). It turns out that under this interpretation our welfare analysis reveals a startling and robust result: the impact of tightening the re-use constraint on welfare is non-monotone.

Alternatively, Kondor and Köszegi (2015) consider an asymmetric information environment where agents are irrational in that they neglect information contained in prices or actions of others. Investors trade on their signals, neglecting the information content of the actions of others. Following Eyster and Rabin (2005) they refer to this behavior as "fully cursed". With this behavior, welfare can simply be evaluated under the objective probabilities. All agents in the economy aim to know these but they receive signals that often mislead them. With this interpretation, however, our baseline calibration seems silly - agents' beliefs are fixed over time, implying that they always receive the exact same signal and never realize their mistakes. We provide an alternative calibration where beliefs change with the exogenous shock which can be interpreted as signals. Under the assumption that agents are fully cursed we obtain the same welfare effect as in the standard calibration: the impact of tightening the re-use constraint on welfare is non-monotone and there is an interior level of calibration which Pareto-dominates all others.

In both exercises we consider unanticipated changes of regulation that occur between two periods. Our starting point is always the setting where no re-use limits apply, $\kappa=1$. The regulator then introduces a re-use limit with a specific $\kappa<1$. It is important to note that the change in welfare depends both on the wealth distribution in the period before the regulatory change and on the exogenous state in the period when the regulation first applies. The wealth distribution matters because it affects both the asset prices and agents' portfolio choices. As we have seen in the previous section, different levels of the re-use limit imply different price and policy functions. The exogenous state matters because it may greatly affect the wealth distribution. In light of these observations, we need to decide for which values of the endogenous and exogenous state we evaluate the change in welfare. We believe that the most reasonable point of departure are the median of the ergodic wealth distribution of the unregulated economy and the exogenous state 3 , which is the mode of the distribution of shocks and represents the normal growth state. We refer to this starting point as the 'benchmark economy' in our discussion below. To demonstrate that the choice of starting point matters only quantitatively but not qualitatively, we also verify that our key results hold for the 10th and the 90th percentile of the ergodic wealth distribution.

\subsection{Rational agents with unknown probabilities}

We first examine welfare effects in our baseline calibration. We follow Brunnermeier et al. (2014) in that we show that regulation can lead to allocations that are Pareto-better under all "reasonable" beliefs. We begin our analysis with the simpler case where we only use the objective beliefs to evaluate welfare. It is useful to discuss this case in detail because it makes clear how regulation can improve welfare. We then turn to the full analysis and evaluate welfare under several beliefs. 


\subsubsection{An introductory example}

Figure VII plots the welfare effects for agent 2 of an unanticipated change in the re-use regulation when the welfare for agent 1 is kept constant by means of transfers. The interior maximum is

Figure VII: Welfare changes as a function of the re-use parameter

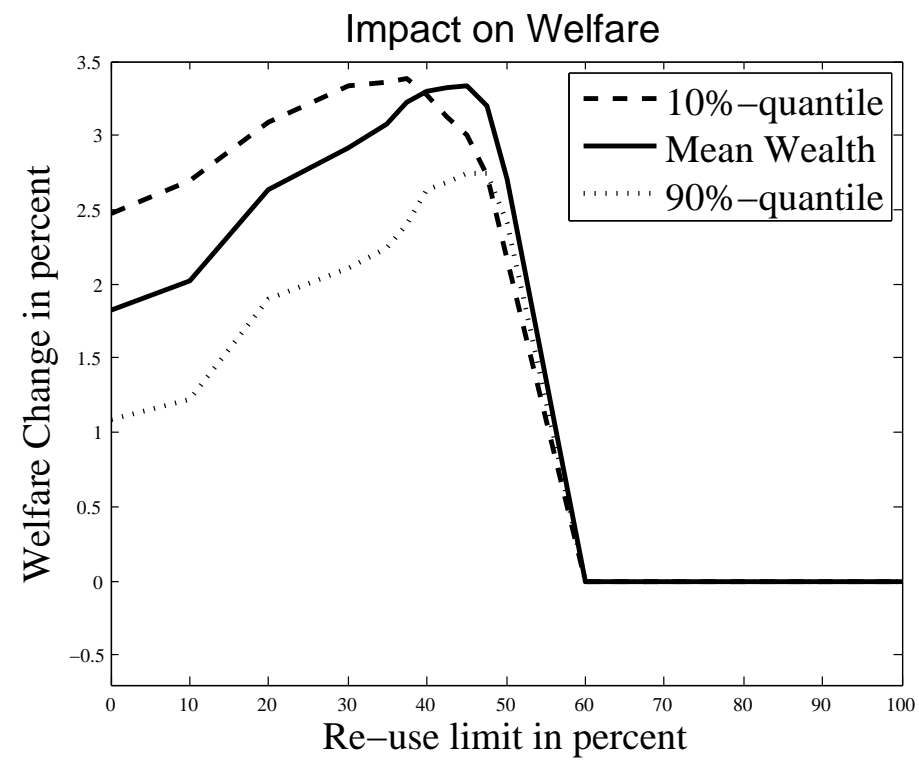

The solid line shows the welfare change for agent 2 after compensating agent 1 for the impact of the regulatory change from $\kappa=1$ to the level of $\kappa$ (in percent) on the horizontal axis. The benchmark economy for the comparison is an unregulated economy in a time period when agent 1's wealth is equal to the mean of the ergodic distribution; also, the economy enters state 3 in the subsequent period. The other two lines report the corresponding welfare changes for an unregulated economy in a time period when agent 1's wealth is equal to the 10th and 90th percentile, respectively.

clearly visible. Figure VIII plots the individual welfare changes for the two agents and also reports the post-compensation change for agent 2 for the benchmark economy. All welfare changes are exactly zero for $\kappa \in[0.6,1]$. For such large values of the re-use parameter, the re-use constraint is never binding in long simulations. The equilibrium is identical to that for an economy with free re-use and a changing regulation of $\kappa$ in this region does not affect equilibrium outcomes. For values of the re-use parameter in the interval $[0.5,0.6]$ (approximately), the regulation leads to a Pareto improvement relative to the unregulated economy. For stricter regulation with smaller values of the re-use parameter, agent 1 gains and agent 2 loses welfare. However, after compensation of agent 2, the net effect on agent 1 remains a positive welfare change.

Two counteracting economic forces are at play here. First, the ability to re-use allows for more risk-sharing in the economy. This effect is generally beneficial for welfare given the agents' heterogeneity in risk aversion. Second, the heterogeneity in agents' beliefs triggers agents to build up leveraged positions beyond what is needed to optimally share risks. As the ability to re-use collateral allows agents to build up this leverage, limiting re-use has the potential to steer agents' choices closer to socially optimal levels.

To demonstrate these two opposing economic forces, we disentangle the effects of heterogeneous 
Figure VIII: Welfare changes as a function of the re-use parameter

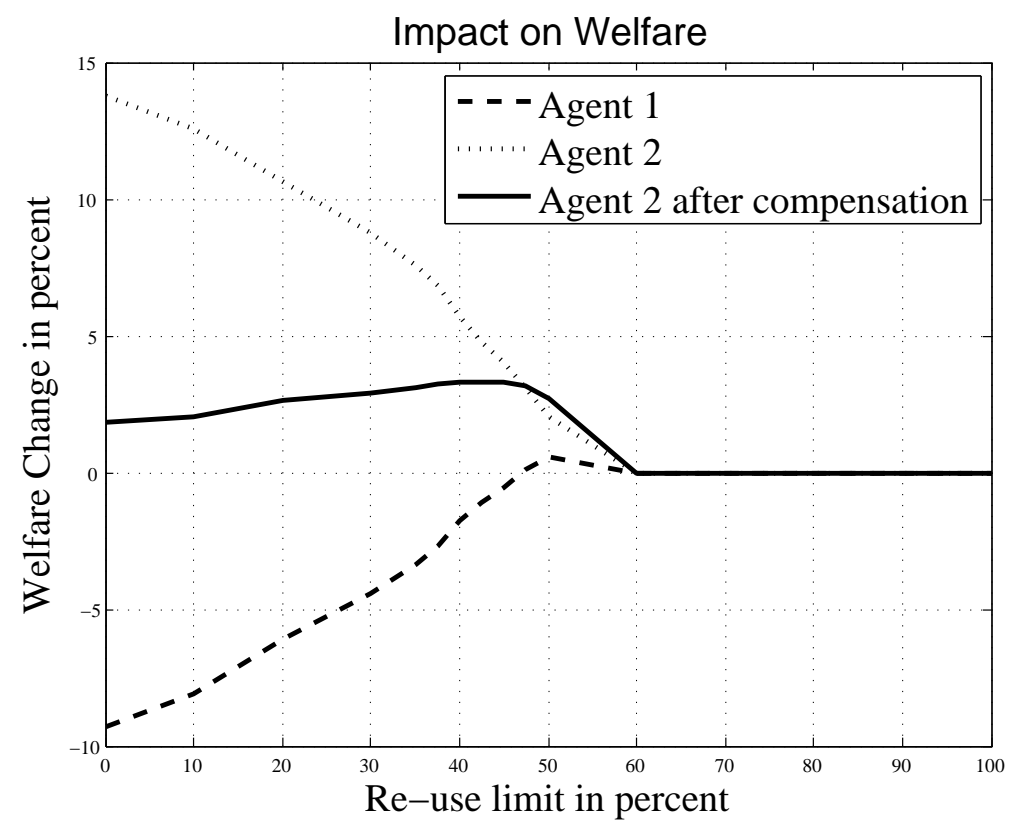

The figure shows the welfare changes for both agents in response to a regulatory change in the re-use parameter from $\kappa=1$ to the level of $\kappa$ on the horizontal axis. The benchmark economy for the comparison is an unregulated economy in a time period when agent 1's wealth is equal to the mean of the ergodic distribution; also, the economy enters state 3 in the subsequent period.

risk aversion and heterogeneous beliefs in two separate experiments. In the first experiment, we set the risk aversion of both agents to 3 and maintain their heterogeneous beliefs. Figure IX plots the individual welfare changes for the two agents in this experiment. Both agents realize substantial welfare gains in response to re-use regulation. In fact, the welfare-maximizing policy (according to the objective beliefs) is a policy prohibiting re-use. This result is not surprising. The agents have heterogeneous beliefs, which are both incorrect. Agent 1 is too optimistic and agent 2 is too pessimistic compared to the objective (and correct) beliefs. The availability of free re-use enables the agents to build up leveraged positions that are suboptimal (according to the objective beliefs). And so strict re-use regulation leads to a Pareto improvement. We also note that the welfare gain of agent 2 , after compensation of agent 1 , shows strong concavity for $\kappa \in[0,0.6]$.

In a second experiment, we set the beliefs of both agents to the objective beliefs and maintain their original levels of risk aversion. Figure $\mathrm{X}$ plots the individual welfare changes for the two agents in this experiment. Due to their heterogeneous levels of risk aversion but identical objective beliefs, the agents trade solely for the purpose of risk-sharing. A decrease of the re-use parameter below $60 \%$ restricts the agents' ability to trade and decreases the welfare of the more risk-averse agent 2 . While the less risk-averse agent 1 gains welfare for some intermediate values of $\kappa$, he also loses welfare once the re-use parameter falls below $30 \%$. The aggregate welfare effect is never positive. Moreover, we find that the welfare of agent 2 after compensation of agent 1 is very much linearly increasing in the re-use limit for $\kappa \in[0,0.6]$.

In sum, for $\kappa \in[0,0.6]$, we observe a concave decreasing welfare of agent 2 after compensation 
Figure IX: Welfare changes as a function of the re-use parameter

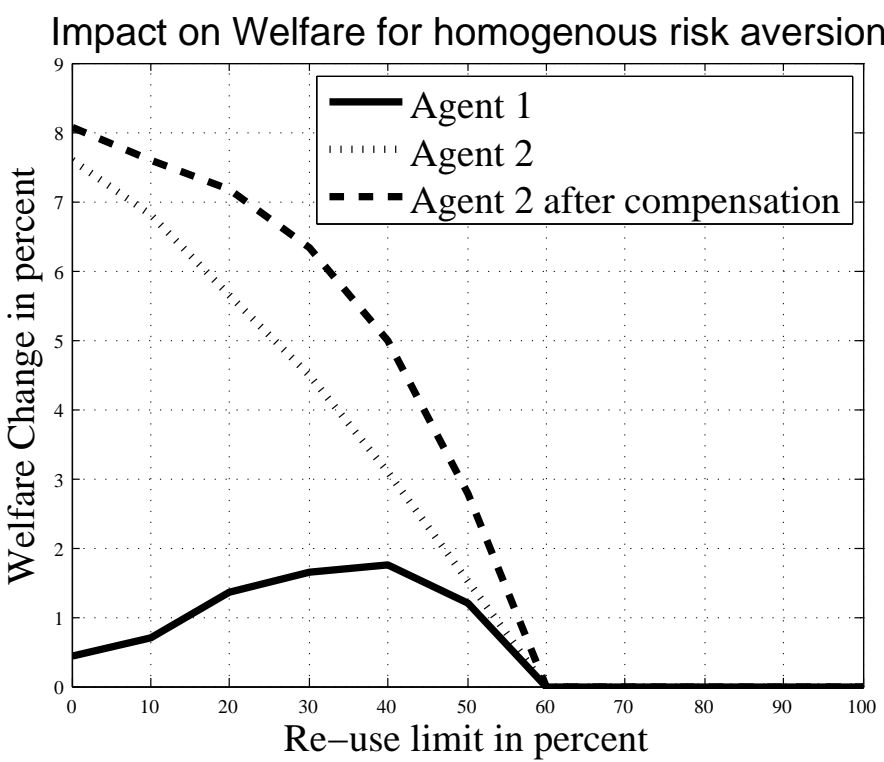

The graph shows welfare changes for the two agents in response to a regulatory change in the re-use parameter from $\kappa=1$ to the level of $\kappa$ on the horizontal axis.. Both agents have identical risk aversion of 3 and the original heterogeneous beliefs.

Figure X: Welfare changes as a function of the re-use parameter

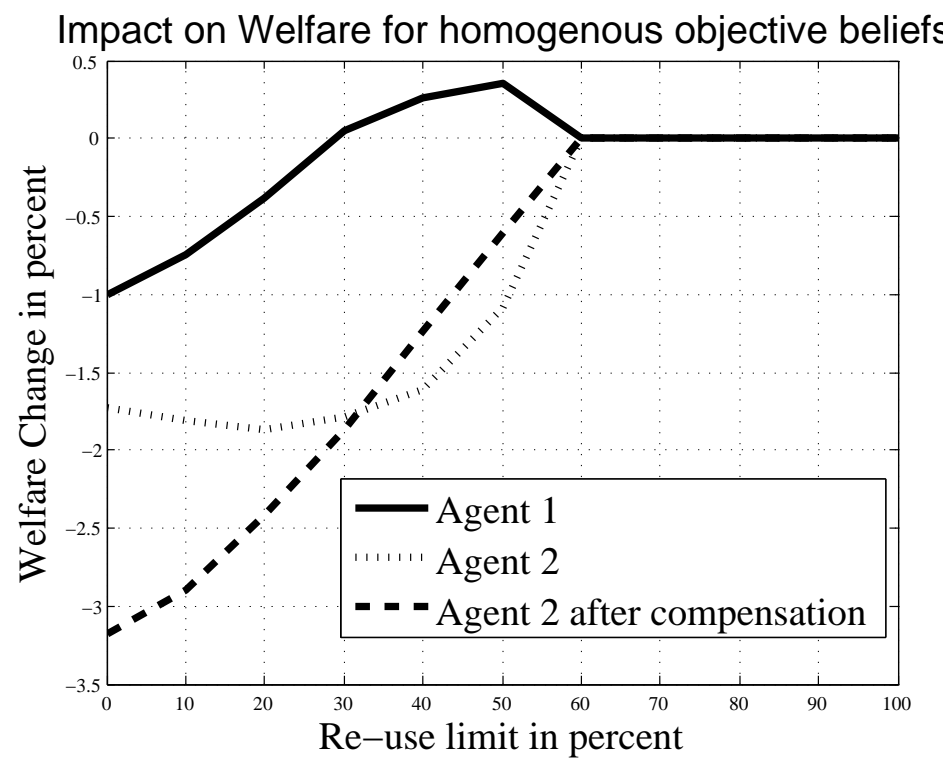

The graph shows welfare changes for the two agents in response to a regulatory change in the re-use parameter from $\kappa=1$ to the level of $\kappa$ on the horizontal axis. Both agents have identical objective beliefs and the original heterogeneous levels of risk aversion. 
of agent 1 in the first experiment and a linear increasing welfare of agent 2 after compensation of agent 1 in the second experiment. Combining these insights, it is not surprising to find the humpshaped impact of the re-use limit on welfare in the original setting with heterogeneous beliefs and heterogeneous risk aversion.

\subsubsection{A full welfare analysis}

Until now we have measured welfare gains using the agents' value functions under objective beliefs. We may question this choice of metric since the agents make their decisions under different beliefs and so we may want to examine welfare under different beliefs as well. Also, perhaps the objective beliefs in the welfare measure are the reason for the interior maxima. In our second robustness check, we examine welfare changes under four alternative sets of beliefs. Two natural alternatives are the individual beliefs of the two agents. In addition, we consider beliefs that are the average of one of the agent's beliefs and the objective beliefs. For each of these four alternatives, we compute again the peak of the welfare of agent 2 after compensation of agent 1 .

Table III reports the results of this robustness check. The table reports the location of the peak

Table III: Sensitivity to choice of the beliefs used to evaluate welfare

\begin{tabular}{|c|c|c|c|c|}
\hline agent 1 & average 1 & benchmark & average 2 & agent 2 \\
\hline $50(2.79)$ & $47.5(3.29)$ & $45(3.33)$ & $37.5(3.24)$ & $37.5(2.91)$ \\
\hline
\end{tabular}

The table reports the location of the peak of the welfare function in terms of the re-use limit $\kappa$ (in percent) as well as the change in welfare (in percent) for agent 2 after compensation of agent 1 at this location (in parentheses) for our economic model for the agents' value functions under different beliefs. The entry under "benchmark" denotes the welfare change under objective beliefs, the entry under "average 1" denotes the welfare change for beliefs that are the average of agent 1's and the objective beliefs, and so on.

of the welfare function in terms of the re-use limit $\kappa$ (in percent) as well as the change in welfare (in percent) for agent 2 after compensation of agent 1 at the peak (in parentheses). The entry under "benchmark" denotes the results under objective beliefs, the entry under "average 1" denotes the results for beliefs that are the average of agent 1's and the objective beliefs, and so on. For all five beliefs, the welfare measure has an interior maximum. Both the locations of the peak and the accompanying maximal welfare gains change only slightly in response to changes in the beliefs.

\subsection{A calibration with cursed agents}

The presence of an interior welfare-maximizing re-use level is a surprising and important prediction of our asset-pricing model. The interested reader may, therefore, wonder whether this outcome holds up to changes in the model set-up or the welfare measure. To address this question, we now consider a model with cursed agents. Until now our analysis has rested on the key assumption that the two agents have different and wrong beliefs at all times. Agent 1 is always optimistic and 
agent 2 is always pessimistic relative to the objective state probabilities. This obviously does not fit the narrative that agents receive signals every period and irrationally act on these signals without considering other agents' actions. We now relax this strong assumption and allow for temporary agreement between the two agents. Specifically, there are two belief regimes, which have the same unconditional probability of 0.5 , and which each persist with a probability of $\pi^{r}$. In the first regime, called the agreement regime, both agents' beliefs are just the objective probabilities. The second regime, called the disagreement regime, is the heterogeneous-beliefs set-up of our benchmark analysis with agent 1 (2) being optimistic (pessimistic).

Recall that in our benchmark analysis, the disagreement parameters had the value $\delta^{d}=\delta^{n}=0.4$, see Section 3.5. We now also consider a smaller value of $\delta^{d}=\delta^{n}=0.2$. Table IV reports the results of this robustness check ${ }^{13}$ for three different values of the persistence probability $\pi^{r}$. Note that the benchmark economy is given by the case $\pi^{r}=1$ and $\delta^{d}=\delta^{n}=0.4$. The table reports the location of the peak of the welfare function in terms of the re-use limit $\kappa$ (in percent) as well as the change in welfare (in percent) for agent 2 after compensation of agent 1 at the peak (in parentheses). The interior welfare-maximizing re-use level is qualitatively robust. In all six cases, the welfare of

Table IV: Sensitivity to level of disagreement and persistence in belief regime

\begin{tabular}{|c||c|c|c|}
\hline persistence $\pi^{r}($ in $\%)$ & 100 & 90 & 50 \\
\hline \hline disagreement $\delta^{d}=\delta^{n}=0.4$ & $45(3.33)$ & $45(1.20)$ & $50(1.14)$ \\
\hline disagreement $\delta^{d}=\delta^{n}=0.2$ & $50(0.60)$ & $50(0.21)$ & $52.5(0.21)$ \\
\hline
\end{tabular}

The table reports the location of the peak of the welfare function in terms of the re-use limit $\kappa$ (in percent) as well as the change in welfare (in percent) for agent 2 after compensation of agent 1 at the peak (in parentheses) for our economic model for different values of the disagreement parameter $\delta^{d}=\delta^{n}$ and the persistence parameter $\pi^{r}$ (in percent).

agent 2 after compensation of agent 1 has an interior maximum. Not surprisingly, a lower level of disagreement leads to smaller maximal welfare gains. Similarly, lower levels of the persistence $\pi^{r}$ of the belief regimes also result in smaller maximal amounts of welfare gains. The results further reveal that the location of the peak shifts to slightly higher values of the re-use limit $\kappa$, compared to the benchmark case.

\section{Conclusion}

Publicly available data on collateral re-use activity of globally active banks indicates that collateral re-use plays an important role in financial markets. While market participants have stressed the importance of re-use of collateral as a source of funding and market liquidity more generally, regulators

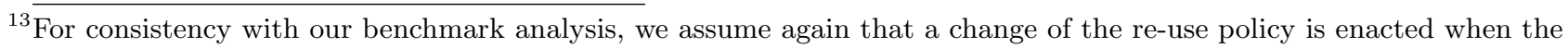
wealth distribution in the economy is at its mean level and the economy enters the normal state of the disagreement regime. This assumption ensures comparability of the results to those of the benchmark economy. 
and supervisors have raised various concerns about this market practice. The use of the same security as underlying collateral for different transactions increases the sum of exposures in the financial system and, and as result, creates leverage across the intermediation chain. To provide information for the policy discussion on whether collateral re-use should be permitted on financial markets, and if so, to what degree, it is clearly important to develop a model framework to understand the (qualitative) implications of collateral re-use on financial market outcomes and welfare.

In this paper, we have developed a calibrated, infinite-horizon asset-pricing model with heterogeneous agents that allows us to assess the qualitative implications of re-use on financial market leverage, volatility, and welfare. In our model, the ability of agents to re-use frees up collateral that can be used to back more transactions. Through this channel, re-use of collateral contributes to the build-up of leverage in the financial system and is found to significantly increase volatility in financial markets. We have shown that the limits on the amount of collateral that agents may re-use reduces financial market volatility; in fact, the tighter the limits the lower the volatility. While the effect of re-use limits on volatility is monotone, the impact on welfare is not. In the model, allowing for some re-use can improve welfare as it enables agents to more effectively share risks. Allowing re-use beyond intermediate levels, however, can lead to excessive leverage and lower welfare. In conclusion, the analysis in this paper provides a rationale for limiting, yet not banning, re-use in financial markets.

\section{Appendix}

\section{A Additional Proofs}

We show that the agents' utility maximization problem is well defined. In particular, we prove that the collateral and lower-bound constraints do not exclude reasonable portfolios.

The collateral constraint (1) only needs to hold for $\theta^{h}\left(s^{t}\right)<0$. We now show that it is redundant for $\theta^{h}\left(s^{t}\right) \geq 0$. Note that (1) is equivalent to

$$
\theta^{h}\left(s^{t}\right) \geq \frac{-\left(1-m_{s}\left(s^{t}\right)\right) p\left(s^{t}\right) \phi^{h}\left(s^{t}\right)}{q\left(s^{t}\right)} .
$$

If $\theta^{h}\left(s^{t}\right) \geq 0$ and $\phi^{h}\left(s^{t}\right) \geq 0$, then the constraint holds since $m_{s}\left(s^{t}\right) \leq 1$. If $\phi^{h}\left(s^{t}\right)<0$, the constraint cannot be binding, since in that case the collateral constraint (2) imposes the tighter constraint

$$
\theta^{h}\left(s^{t}\right) \geq \frac{-p\left(s^{t}\right) \phi^{h}\left(s^{t}\right)}{\left(1-m_{l}\left(s^{t}\right)\right) q\left(s^{t}\right)}
$$

for all $m_{s}\left(s^{t}\right), m_{l}\left(s^{t}\right)<1$.

The collateral constraint (2) only needs to hold for $\phi^{h}\left(s^{t}\right)<0$. We now show that it is redundant for $\phi^{h}\left(s^{t}\right) \geq 0$. Note that $(2)$ is equivalent to

$$
\phi^{h}\left(s^{t}\right) \geq \frac{-\left(1-m_{l}\left(s^{t}\right)\right) q\left(s^{t}\right) \theta^{h}\left(s^{t}\right)}{p\left(s^{t}\right)} .
$$


If $\theta^{h}\left(s^{t}\right) \geq 0$ and $\phi^{h}\left(s^{t}\right) \geq 0$, then the constraint holds since $m_{s}\left(s^{t}\right) \leq 1$. If $\theta^{h}\left(s^{t}\right)<0$, the constraint cannot be binding, since in that case the collateral constraint (1) imposes the tighter constraint

$$
\theta^{h}\left(s^{t}\right) \geq \frac{-q\left(s^{t}\right) \theta^{h}\left(s^{t}\right)}{\left(1-m_{s}\left(s^{t}\right)\right) p\left(s^{t}\right)}
$$

for all $m_{s}\left(s^{t}\right), m_{l}\left(s^{t}\right)<1$.

\section{References}

Andolfatto, D., F. M. Martin, and S. Zhang (2015). Rehypothecation and liquidity. FRB St Louis Paper No. FEDLWP2015-003.

Aragon, G. O. and P. E. Strahan (2012). Hedge funds as liquidity providers: Evidence from the lehman bankruptcy. Journal of Financial Economics 103(3), 570-587.

Barro, R. (2009). Rare disasters, asset prices, and welfare costs. The American Economic Review 99(1), 243-264.

Barro, R. and T. Jin (2011). On the size distribution of macroeconomic disasters. Econometrica $79(5), 1567-1589$.

Barro, R. and J. Ursúa (2008). Macroeconomic crises since 1870. Brookings Papers on Economic Activity.

Bottazzi, J.-M., J. Luque, and M. R. Páscoa (2012). Securities market theory: Possession, repo and rehypothecation. Journal of Economic Theory 147(2), 477-500.

Brumm, J., M. Grill, F. Kubler, and K. Schmedders (2015). Collateral requirements and asset prices. International Economic Review 56(1), 1-25.

Brunnermeier, M. K., A. Simsek, and W. Xiong (2014). A welfare criterion for models with distorted beliefs. The Quarterly Journal of Economics 129(4), 1753-1797.

Duffie, D. (2010). The failure mechanics of dealer banks. Journal of Economic Perspectives 24(1), $51-72$.

Epstein, L. and S. Zin (1989). Substitution, risk aversion, and the temporal behavior of consumption and asset returns: A theoretical framework. Econometrica 57, 937-969.

Eren, E. (2014). Intermediary funding liquidity and rehypothecation as determinants of repo haircuts and interest rates. In 27th Australasian Finance and Banking Conference.

Eyster, E. and M. Rabin (2005). Cursed equilibrium. Econometrica 73(5), 1623-1672.

Fostel, A. and J. Geanakoplos (2008). Leverage cycles and the anxious economy. American Economic Review 98(4), 1211-1244. 
FSB (2013). Policy framework for addressing shadow banking risks in securities lending and repos. Financial Stability Board, Policy Report.

FSB (2017a). Non-cash collateral re-use: Measure and metrics. Financial Stability Board, Policy Report.

FSB (2017b). Re-hypothecation and collateral re-use: Potential financial stability issues, market evolution and regulatory approaches. Financial Stability Board, Policy Report.

Geanakoplos, J. (1997). Promises, promises. Proceedings of the Santa Fe Institute (BW Arthur, SN Durlauf, and DA Lane, Eds.), Addison-Wesley, Reading, MA in The Economy as an Evolving Complex System II.

Geanakoplos, J. and W. Zame (2002). Collateral and the enforcement of intertemporal contracts. discussion paper, Yale University.

Gilboa, I., L. Samuelson, and D. Schmeidler (2014). No-betting-pareto dominance. Econometrica 82(4), 1405-1442.

Gottardi, P., V. Maurin, and C. Monnet (2015). A theory of repurchase agreements, collateral re-use and intermediation.

Infante, S. (2014). Liquidity windfalls: The consequences of repo rehypothecation. Finance and Economics Discussion Series, Board of Governors of the Federal Reserve System (U.S.) (2015022).

Kirk, A. M., J. McAndrews, P. Sastry, and P. Weed (2014). Matching collateral supply and financing demands in dealer banks. Economic Policy Review.

Kondor, P. and B. Köszegi (2015). Cursed financial innovation. Working Paper.

Maurin, V. (2015). Re-using collateral a general equilibrium model of rehypothecation.

Singh, M. (2011). Velocity of pledged collateral: analysis and implications. IMF Working Papers, $1-24$.

Singh, M. (2014). Collateral and Financial Plumbing 2nd Impression. Risk Books.

Singh, M. and J. Aitken (2010). The (sizable) role of rehypothecation in the shadow banking system. IMF Working Papers, 1-15. 